\section{IMPACTO ECONÓMICO OCASIONADO POR TORMENTAS SEVERAS EN MUNICIPIOS DEL ÁREA METROPOLITANA DE ASUNCIÓN, PARAGUAY}

Fabricio Vazquez $^{1, *}$ y Teresa Gamarra ${ }^{1}$

\section{RESUMEN}

En los últimos años en el Área Metropolitana de Asunción (AMA), el impacto de las tormentas severas ha cobrado vidas humanas y afectado negativamente en la economía de las empresas ubicadas en los municipios de esta área geográfica. Este estudio aborda la problemática de los efectos económicos causados por este fenómeno, específicamente, las precipitaciones que desencadenan inundaciones pluviales en zonas urbanas del AMA y su efecto en el desempeño económico de las unidades productivas ubicadas en el corredor económico de los municipios de Lambaré, San Lorenzo, Mariano Roque Alonso, Ñemby, Fernando de la Mora, Limpio, Luque y Villa Elisa, reduciendo las ventas del comercio principalmente. Las cifras de pérdidas de los comercios y servicios en las ciudades estudiadas son elevadas para las economías urbanas como lo demuestra este estudio, el cual desarrolla un escenario sobre quince eventos en el término de un año, poniendo en valor lo que cada comerciante deja de vender cuando aparecen estas tormentas que desencadenan inundaciones urbanas. Las tormentas severas son comunes y frecuentes entre los meses de septiembre a mayo cada año en estos lugares, y si bien su aparición es periódica, los efectos que causan las mismas repercuten significativamente en las economías locales, entre otros efectos.

\section{PALABRAS CLAVE}

Tormentas severas, Impacto, Economía, Inundaciones pluviales, Área Metropolitana de Asunción

\section{ECONOMIC IMPACT CAUSED BY SEVERE STORMS IN MUNICIPALITIES OF THE ASUNCIÓN METROPOLITAN AREA, PARAGUAY}

\section{ABSTRACT}

In recent years, the impact of severe storms has claimed human lives and adversely affected the economy of companies located in the municipalities of the Metropolitan Area of Asunción (AMA). This study addresses the problem of the economic effects caused by this phenomenon, specifically, the precipitations that trigger rainwater flooding in urban areas of the AMA and its effect on the economic performance of the productive units located in the economic corridor of the municipalities of Lambaré, San Lorenzo, Mariano Roque Alonso, Nemby, Fernando de la Mora, Limpio, Luque and Villa Elisa, mainly by reducing sales. The trade and services sector losses in the studied cities have a high impact on urban economies, as demonstrated by this study. We developed a scenario of fifteen severe storm events -in the term of one year- and put into value what each trader stops selling when these storms occur and trigger flooding in urban areas. Severe storms are common and frequent between September and May each year in the selected area, and although their occurrence is periodic, their effects have a significant impact on local economies and other sectors.

\section{KEYWORDS}

Severe storms, Impact, Economy, Rainwater floods, Asunción Metropolitan Area
1. Centro de Tecnología Apropiada, Facultad de Ciencias y Tecnología, Universidad Católica Nuestra Señora de la Asunción, Asunción, Paraguay.

*Autor de correspondencia: fabricio.vazquez@gmail.com

\section{RECIBIDO}

22 de julio de 2018

\section{ACEPTADO}

17 de septiembre de 2018

\section{PUBLICADO}

1 de julio de 2019

\section{Formato cita}

Recomendada (APA): Vázquez, F. \& Gamarra, T. (2019). Impacto económico ocasionado por tormentas severas en municipios del Área Metropolitana de Asunción, Paraguay. Revista de Estudios Latinoamericanos sobre Reducción del Riesgo de Desastres REDER, 3(2), 1-16.

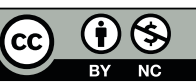

Todos los artículos publicados en REDER siguen una política de Acceso

Abierto y se respaldan en una Licencia CreativeCommons Atribución-NoComercial 4.0 Internacional.

\section{Revista de Estudios}

Latinoamericanos sobre Reducción del Riesgo de Desastres (REDER)

Diseño: Lupe Bezzina Tipografia: Hospital 


\section{INTRODUCCIÓN}

El Área Metropolitana de Asunción (AMA), con una población de 2.3 millones de habitantes, representa el $30 \%$ de la población de Paraguay, se constituye en las 10 aglomeraciones urbanas más grandes de América del Sur, con una extensión de $1.029 \mathrm{~km} 2$ y un total de 12 distritos, junto con las ciudades de su periferia; Luque, Fernando de la Mora, San Lorenzo, Villa Lisa, Lambare, Mariano Roque Alonzo, Nemby, Capiata, Limpio, Aregua, San Antonio, Ypané e Itaugua todos ellos tamben conforman el Departamento Central.

El AMA tiene una posición privilegiada en términos de disponibilidad hídrica que yace a orillas de uno de los más grandes ríos de América del Sur, el río Paraguay, ademas recibe recursos del agua subterránea del acuífero Patiño. No obstante, esta zona, tiene problemas graves relacionados a la gestión hídrica, tales como la falta de tratamiento de aguas residuales, la baja eficacia en la recolección y tratamiento de residuos sólidos y los problemas asociados al drenaje urbano que afectan a la calidad de los cuerpos de agua que abastecen a Asunción, poniendo en riesgo la salud de la población urbana.

La expansion urbana ha sido en las ultimas cuatro decadas, muy desordenada y desprovista de ejercios de planificacion y anticipacion, en este sentido la ciudad de Asuncion ha sido el principal polo urbano del pais y su crecimiento demografico se ha producido principalmente por migracion interna. La debilidad institucional no ha logrado revertir el poblamiento inercial desordenado del espacio urbano y sus consecuencias. Tampoco se realizaron las inversiones en infraestructuras que hubiesen permitido una mejor gestion y administracion de las precipitaciones mediantes redes de evacuacion de las aguas de lluvias.

El desarrollo urbano, la pavimentación y la proporción cada vez menor de espacios verdes en relación con las zonas edificadas traen como consecuencia un aumento notable de los escurrimientos pluviales en las ciudades. La urbanización en una cuenca tiende a llenar las áreas bajas (almacenamiento) y a pavimentar áreas permeables (infiltración).

Las inundaciones en zonas urbanas, ocurren en áreas localizadas en proximidades de los sectores más bajos de calles y/o avenidas, estas pueden ser constantes $u$ ocasionales, en el contexto urbano la atención a los problemas del drenaje urbano generalmente se realiza solo inmediatamente después de su ocurrencia, y además muchas veces es olvidado con el pasar del tiempo, durante periodos de sequía.

El impacto de las lluvias, con sus diferentes intensidades, provoca impactos significativos en las actividades económicas urbanas, al limitar, reducir y a veces impedir el desarrollo comercial de las ciudades, ademas de las tormentas severas que son frecuentes entre los meses de setiembre y mayo de cada año. Excepcionalmente, en este periodo se generan tormentas de gran intensidad asociadas con granizos, vientos fuertes y lluvias, cuyos volúmenes diarios e intensidad pueden superar los promedios de todo un mes, estas lluvias afectan e interfieren las actividades humanas con diferentes intensidades e impactan significativamente en las economías locales, especialmente en el sector comercial y de servicios.

En este sentido, se recuerda que solo en el AMA, especificamente en la ciudad de Mariano Roque Alonso, el tornado del 21 de setiembre de 2012 provoco la muerte de cinco personas, o bien la granizada del 22 de setiembre de 2013 que afectó vastas zonas de Itauguá, Aregua, entre otras ciudades, provocando daños materiales de gran envergadura. Se destacan igualmente los eventos de lluvias intensas de noviembre de los años 2012 y 2013, o bien la nueva marca histórica registrada en Luque el 26 de febrero de 2014, donde en tan solo cinco horas se registraron $228 \mathrm{~mm}$ de lluvia, equivalente a dos veces el promedio mensual de aquel mes.

La problemática relacionada con los Arroyos Urbanos del AMA y las inundaciones ocasionadas por las tormentas severas, no es nueva; la ocupación de márgenes, el vertido de residuos sólidos y efluentes domésticos e industriales, y la urbanización no planificada son los factores que alteran estos cursos de agua, que durante un evento severo y ante la abundancia de precipitaciones, los cauces de los arroyos, especialmente aquellos que cruzan más de dos o tres municipios colapsan y generan desbordamientos.

El objetivo principal del análisis económico fue identificar y contabilizar el impacto económico de las precipitaciones en general y de las inundaciones en particular, en ocho municipalidades del AMA: Lambaré, San Lorenzo, Mariano Roque Alonso, Ñemby, Fernando de la Mora, Limpio, Luque y 
Villa Elisa, que son las que tienen que gestionar estas situaciones, asi como el sector comercial y de servicios, que se sienten afectados directamente por la disminución de las ventas.

El proceso de relevantamiento de datos requirió de la identificación y selección de los principales corredores comerciales, a partir de los datos estadísticos disponibles en el Censo Económico del año 2011 así como del Pre Censo de Población y Viviendas del año 2012. Los datos recolectados se orientaron principalmente hacia el impacto, positivo o negativo, de las lluvias sobre la actividad comercial, es decir sobre las ventas y los márgenes de rentabilidad de los mismos. De forma complementaria se realizaron observaciones sobre las instalaciones físicas de los comercios, de forma a relevar adaptaciones edilicias a las inundaciones.

Atendiendo los umbrales establecidos por la Dirección de Meteorologia e Hidrologia (DMH) y la Secretaria de Emergencia Nacional en el marco del establecimiento del Protocolo de Alerta Temprana (2017), iniciativa facilitada por la Universidad Católica Nuestra Señora de la Asunción, para Inundaciones Pluviales/Intensidad de lluvias, la afectación por los siguiente umbrales difieren según el área geográfica donde se registran y estos son:

- Superior a $80 \mathrm{~mm} /$ día posibles inundaciones extremas a nivel de distritos y departamento

- Superior $50 \mathrm{~mm} / \mathrm{h}$. posibles inundaciones importantes que podrían llegar a escala de barrios (municipios).

- 30 a $50 \mathrm{~mm} / \mathrm{h}$. posibles raudales e inundaciones muy temporales en zonas bajas y muy vulnerables.

En cuanto al impacto de las precipitaciones, se asume que las lluvias superiores a 80 $\mathrm{mm} /$ día, las consideradas lluvias fuertes, generan inundaciones extremas a nivel de distritos, (según el ordenamiento juridico del Paraguay municipios tambien denominados distritos son subdivisiones de los departamentos y de menores circunscripciones politico administrativo del pais) y departamentos. Las precipitaciones superiores a $50 \mathrm{~mm} / \mathrm{h}$ pueden producir inundaciones importantes que podrían llegar a escala de barrios (unidad mas pequeña territorial, un conjunto de barrios forma parte de un distrito o municipio).

Finalmente, las lluvias de entre 30 y $50 \mathrm{~mm} / \mathrm{h}$ generan raudales e inundaciones muy temporales en zonas bajas y muy vulnerables. El mayor o menor impacto de las precipitaciones se determina por tres factores principales: la inexistencia de infraestructura de desague pluvial, la presencia de arroyos y, por ultimo, la topografia del terreno, donde las zonas mas bajas reciben grandes cantidades de agua proveniente de las zonas mas alta, magnificando el efecto de las precipitaciones. Se aclara que tanto la ciudad de Asuncion como las del Gran Asuncion o su Area Metroplitana no presentan diferencias de altura muy pronunciadas, ni desniveles considerables, como podrian obserevarse en ciudades ubicadas en las laderas de cerros, pero que debido a la combinacion de volumenes considerables de precipitaciones y desniveles en la topografia terminan generando un alto impacto en la vida cotidiana de las ciudades

Si bien las lluvias generan inundaciones las mismas pueden mostrar distintas intensidades. Las inundaciones mayores se caracterizan por inundaciones extensas de estructuras y de calles a nivel de barrios, distritos y departamentos, requiriendo necesidad de evacuación de personas y/o transferencia de bienes a elevaciones más altas. Las inundaciones moderadas comprenden algunas inundaciones de estructuras y vías cerca de los ríos y arroyos. Por último, las inundaciones menores tienen un efecto mínimo o ningún daño a los bienes, pero generan limitaciones y alteracciones al funcionamiento de la ciudad, las ventas y prestaciones de servicios.

En las observaciones directa realizadas a lo largo de este estudio, se ha podido notar una conducta social tradicional, manifiesta, en conversaciones con los comerciantes de la zona, que en los periodos o días de lluvia se caracteriza por la cancelación o retraso de las salidas del hogar, esto se debe a que la seguridad para moverse en las zonas urbanas se dificulta y limita por la inaccesibilidad al sistema de transporte urbano y vial, y con esto el sector comercial y de servicios, porque las personas prefieren quedarse en sus domicilios y trabajos y restringir al máximo los desplazamientos cotidianos. No debe olvidarse la presencia de patrones culturales rurales, donde las actividades se reducen bastante los dias de lluvia y se dedican al reposo en el hogar, ante la imposibilidad de realizar trabajos en el agro. 


\section{METODOLOGIA}

El enfoque del estudio fue calcular de forma aproximada el impacto económico de las inundaciones pluviales, casi siempre negativo, en los ejes comerciales de las ocho ciudades seleccionadas del AMA. Desde un abordaje exploratorio se determinó una muestra de veinte casos por cada uno de los corredores comerciales de las ciudades estudiadas.

Para calcular el impacto económico de las inundaciones pluviales en estos municipios, se realizaron una serie de actividades orientadas a identificar los lugares en las ciudades que serían susceptibles de tener cier to tipo de impacto económico, generalmente negativo como consecuencia de las inundaciones pluviales que se producen cuando existen lluvias que superan la capacidad de escurrimiento.

A partir de la información existente, especialmente el Censo Económico Nacional (DGEEC, 2011), que revela la cantidad de comercios y servicios existen por cada ciudad, se pudo conocer la relevancia de estos subsectores económicos. Además, las zonas urbanas se caracterizan principalmente por actividades económicas asociadas directamente al comercio y a los servicios con distintas características.

Otra fuente de datos importante fue el Pre Censo de Población y Viviendas realizado en 2012, ya que el mismo geo-referenció los locales comerciales y de servicios de todas las ciudades del país. En este caso, mediante un tratamiento básico en los softwares de georreferenciamiento, permitió determinar los corredores comerciales de cada ciudad, es decir aquellas zonas donde existían una mayor concentración de comercios y servicios.

Por lo general, y siguiendo un patrón cultural muy afirmado, las avenidas, calles y rutas son las zonas de actividad comercial más dinámica pues las mismas están asfaltadas, atrayendo a automovilistas y a unidades del transporte público lo que termina por atraer a los transeúntes y usuarios del transporte público. De esta forma, se seleccionó al menos un eje comercial para cada ciudad, donde luego fueron aplicados cuestionarios con preguntas semi-abiertas en al menos treinta comercios y locales de servicios de cada eje comercial. El instrumento se orientó a relevar la disminución de las ventas en función al tamaño o envergadura de las precipitaciones. Los resultados obtenidos fueron procesados obteniéndose frecuencias y promedios, para luego ser presentadas en el formato de gráficos y cuadros.

\section{PRINCIPALES RESULTADOS}

A partir del procesamiento y análisis de los datos de campo y las observaciones que se realizaron se presentan a continuación los principales resultados.

El primer dato relevante es la cantidad de unidades económicas (ver Figura 1), es decir comercios, servicios e industrias que existen en cada municipio. De igual forma, se aprecia la relevancia en la generación de empleos de las unidades económicas. Por lo general, las ciudades más pobladas tienen más unidades económicas y por lo tanto mayor población dedicada a estos sectores económicos.

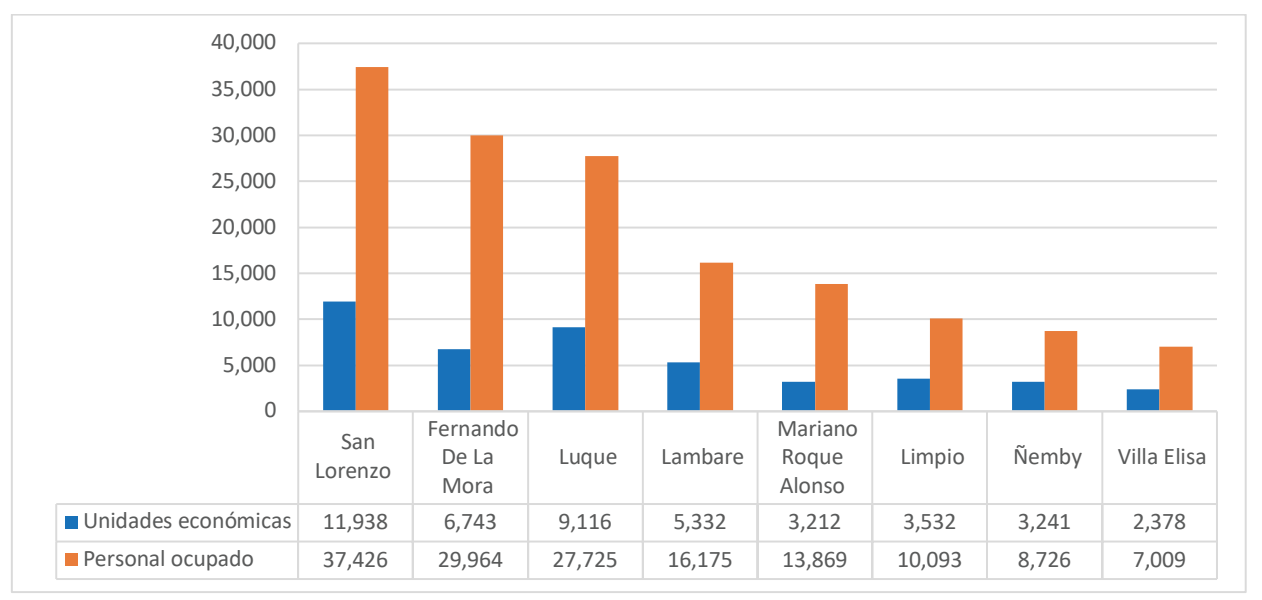

Figura 1. Unidades económicas y personal ocupado por ciudad Fuente: Censo Económico Nacional, 2012. 
El análisis en cuanto a la composición por tipo de actividades sobresale nítidamente el sector comercial (ver Figura 2), seguido de cerca en la mayoría de las ciudades por el sector de servicios, mientras que el industrial no presenta mayor relevancia en los sistemas económicos urbanos, al menos desde la perspectiva de análisis de este estudio.

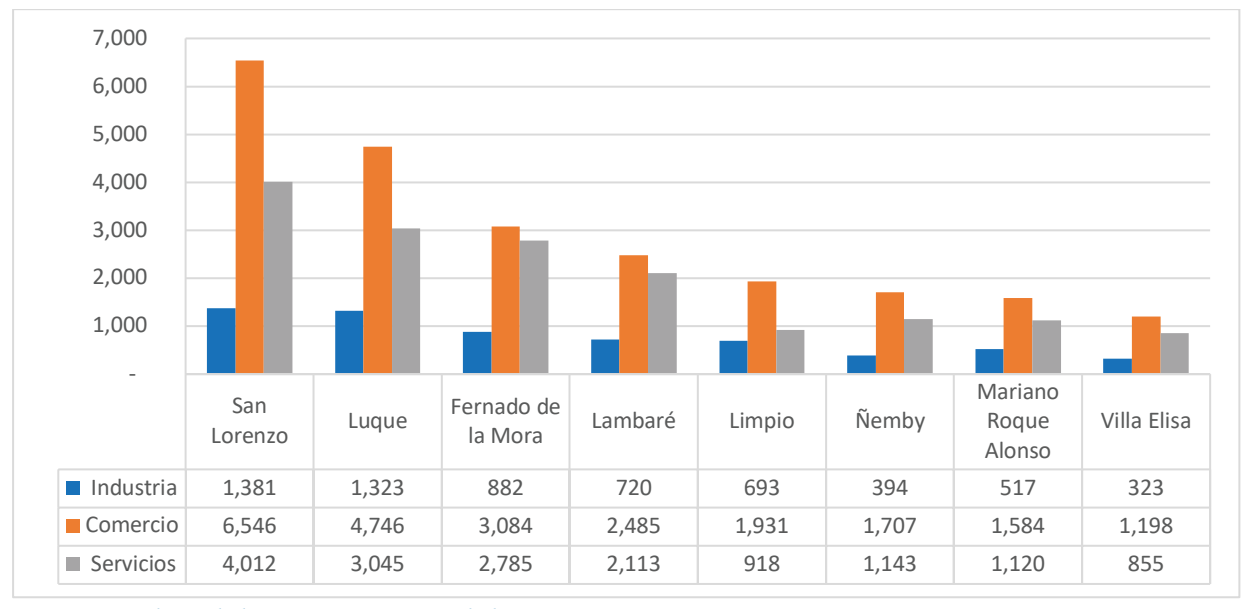

Figura 2. Tipo de unidades económicas por ciudad Fuente: Censo Económico Nacional, 2012.

Aunque los pilares principales de la economía paraguaya siguen siendo la agricultura y la ganadería, con sus sub-sectores vinculados, el sector de comercios y servicios ha tenido un crecimiento sostenido en los últimos años (Ferreira \& Vazquez, 2015, p. 9). En los periodos de menor crecimiento económico, debido principalmente a problemas en la agricultura debido a sequias, el sector de comercios y servicios amortiguó bastante la caída del Producto Interno Bruto, como se observa en la Figura 3.

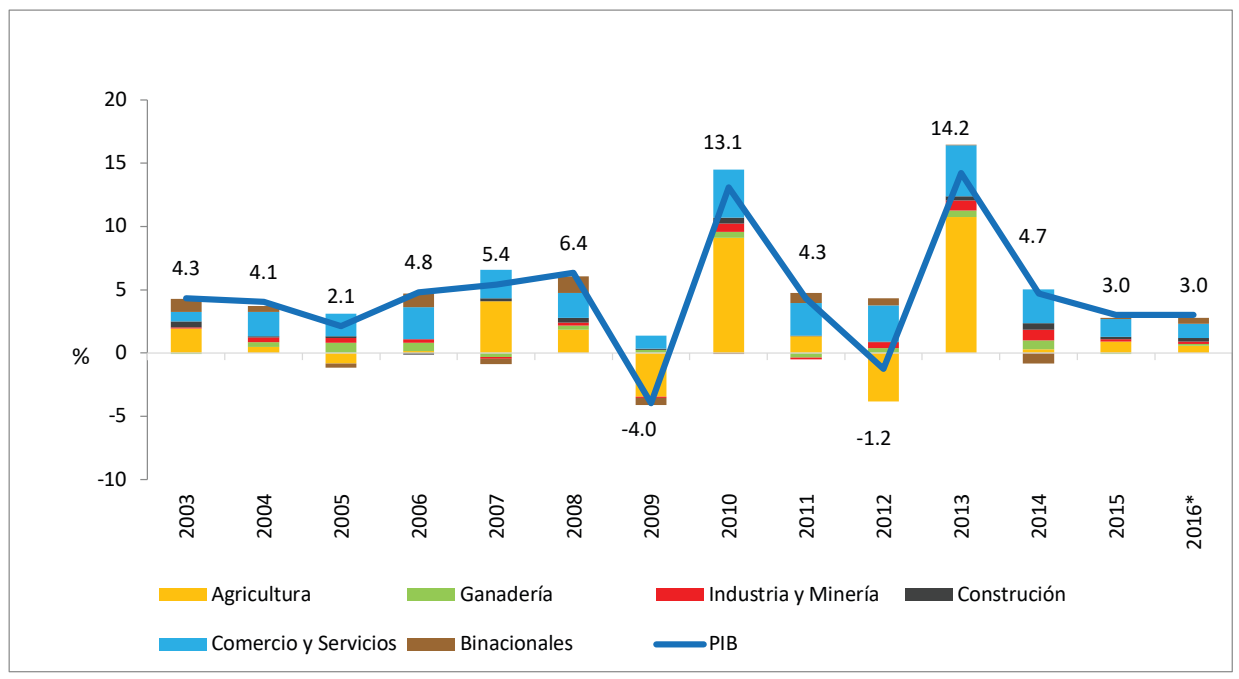

Figura 3. Producto Interno Bruto de Paraguay 2003-2016, por sectores Fuente: Autores, 2019

A continuación, la Tabla 1 indica la clasificación de los tipos de actividades, unidades económicas y personal ocupado para el sector de servicios. La Tabla 2 es indicativo para el sector comercial. Como puede observarse el sector del comercio 'al por menor' o pequeño es el más numeroso, asi como el que mayor cantidad de personas emplea y por lo tanto el mas expuesto a las variaciones del ritmo de actividades. 


\begin{tabular}{lll}
$\begin{array}{l}\text { Principales ramas de actividad del Sector Servicios en el } \\
\text { departamento Central }\end{array}$ & $\begin{array}{l}\text { Unidades } \\
\text { económicas }\end{array}$ & $\begin{array}{l}\text { Total personal } \\
\text { ocupado }\end{array}$ \\
\hline Restaurantes, bares y similares & 5.482 & 10.992 \\
\hline Otras actividades de servicios personales & 2.856 & 4.575 \\
\hline Otros tipos de transporte por vía terrestre & 2.597 & 9.981 \\
\hline Reparación de efectos de uso personal y doméstico & 2.389 & 3.419 \\
\hline Telecomunicaciones & 898 & 2.274 \\
\hline Actividades de médicos y odontólogos & 858 & 1.559 \\
\hline Otros tipos de enseñanza & 493 & 1.404 \\
\hline Actividades jurídicas & 466 & 909 \\
\hline Actividades de juegos de azar y apuestas & 429 & 697 \\
\hline Reparación de equipos informáticos y de comunicaciones & 351 & 670 \\
\hline Abastecimiento de eventos y otros servicios de comida & 345 & 792 \\
\hline Alquiler y arrendamiento de efectos personales y enseres domésticos & 338 & 1.025 \\
\hline Total Servicios & 22.305 & 71.122 \\
\hline
\end{tabular}

Tabla 1. Actividades, unidades económicas y personal ocupado del sector servicio Fuente: Censo Económico Nacional, 2012.

\begin{tabular}{|c|c|c|}
\hline Principales ramas de actividad del Sector Comercial en el departamento Central & $\begin{array}{l}\text { Unidades } \\
\text { económicas }\end{array}$ & $\begin{array}{l}\text { Total personal } \\
\text { ocupado }\end{array}$ \\
\hline Comercio al por menor en comercios no especializados & 16.615 & 35.176 \\
\hline Comercio al por menor de otros artículos en comercios especializados & 4.145 & 9.501 \\
\hline Mantenimiento y reparación de vehículos automotores, excepto motocicletas & 3.597 & 9.160 \\
\hline Comercio al por menor de alimentos, bebidas y tabaco en comercios especializados & 3.351 & 6.063 \\
\hline Comercio al por menor de otros artículos y equipos de uso doméstico en comercios especializados & 2.254 & 6.855 \\
\hline Comercio al por menor de bienes culturales y recreativos en comercios especializados & 965 & 1.741 \\
\hline Comercio al por mayor de otros productos especializados & 742 & 3.061 \\
\hline Comercio, mantenimiento y reparación de motocicletas y de sus piezas y accesorios & 672 & 1.679 \\
\hline Comercio de piezas y accesorios de vehículos automotores, excepto motocicletas & 611 & 2.472 \\
\hline Comercio al por menor en puestos y mercados & 563 & 845 \\
\hline Comercio al por menor de combustible para vehículos automotores en comercios especializados & 465 & 2.909 \\
\hline Comercio al por menor de equipos de información y comunicaciones en comercios especializados & 419 & 973 \\
\hline Comercio al por mayor de alimentos, bebidas y tabaco & 299 & 4.348 \\
\hline Comercio de vehículos automotores, excepto motocicletas & 296 & 1.160 \\
\hline Comercio al por mayor de enseres domésticos & 175 & 2.430 \\
\hline Total Comercio & 35.367 & 89.979 \\
\hline
\end{tabular}

Tabla 2. Actividades, unidades económicas y personal ocupado del sector comercial

Fuente: Censo Económico Nacional, 2012.

La Figura 4 presenta los resultados relacionados al impacto de las precipitaciones en el sector comercial y de servicios. Al analizar por tipo de lluvias, clasificadas en grandes, medianas y ligeras, se aprecia que las lluvias grandes o tormentas tienen un efecto negativo muy significativo. El principal impacto es la reducción de la actividad comercial, entendida como disminución de afluencia de clientes y por lo tanto una menor cantidad de ventas y de rentabilidad (ver Figura 4). Todos los entrevistados del sector comercial y de servicios manifestaron verse afectados de alguna forma por las lluvias severas. Los niveles de impacto muestran que el 34,7\% de ellos manifestaron una reducción en sus ventas de hasta un 50\% durante los días de lluvias grandes. Algunos, el 10,9\% de los entrevistados, manifestaron que las lluvias grandes reducían sus ventas en un $80 \%$. 


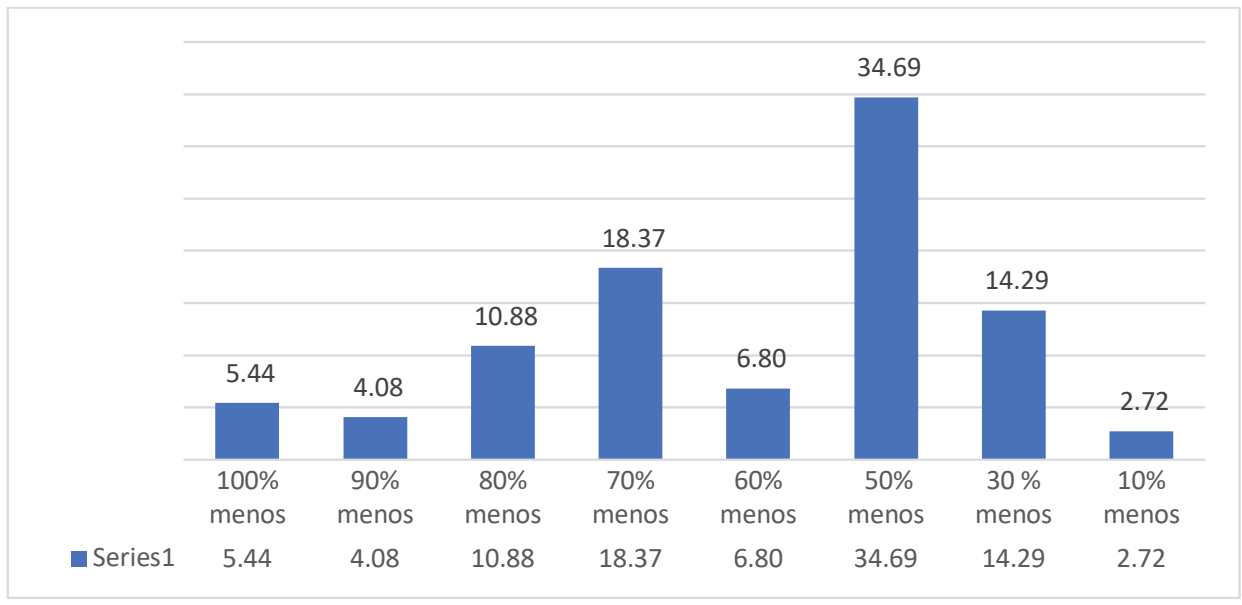

Figura 4. Afectación negativa al comercio en días de lluvias grandes en las ciudades estudiadas, en \% Fuente: Autores, 2019

Al analizar los resultados por ciudades (Figura 5) se observan diferencias sensibles debido principalmente a la ubicación geográfica de los corredores comerciales, la topografía y la existencia de cursos de agua naturales (arroyos) próximos a los corredores.

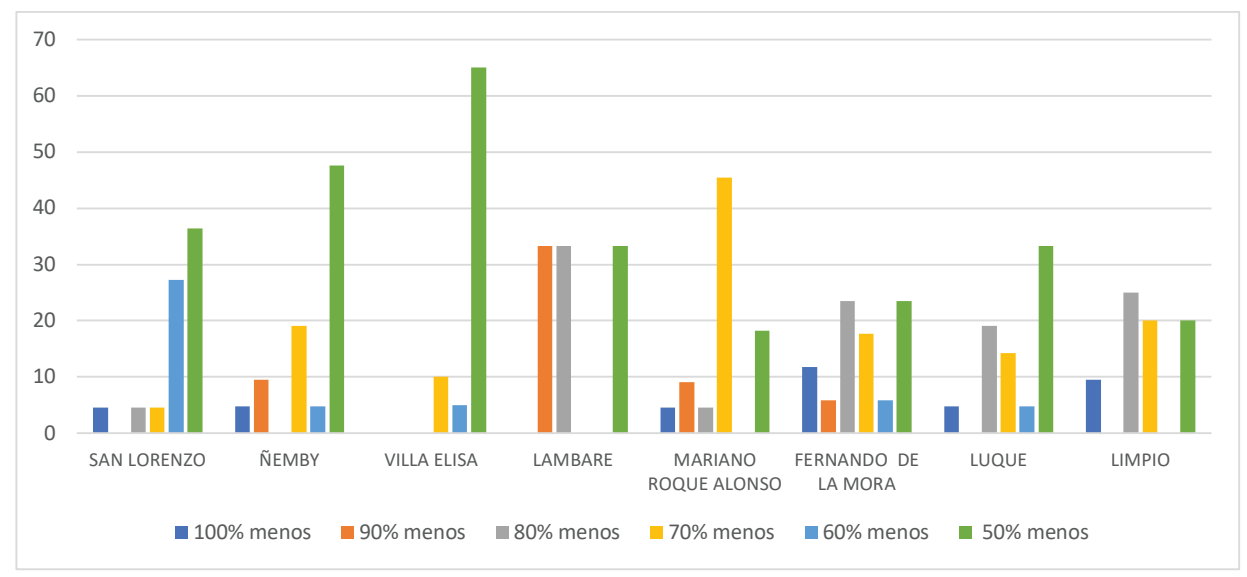

Figura 5. Caída en las ventas en días de lluvias grandes, en $\%$

Fuente: Autores, 2019.

El impacto de las lluvias medias (Figura 6) en el conjunto de ciudades estudiadas es necesariamente inferior a las lluvias grandes, aunque en niveles relativamente elevados. Así, $40 \%$ de los encuestados manifestó que este tipo de lluvia hace disminuir sus ventas en un $30 \%$, mientras que el $26,9 \%$ de los comerciantes indicaron que la disminución de las ventas era del $10 \%$. Un $21,4 \%$ de los encuestados manifestaron que las lluvias medias les provocaba una disminución del $50 \%$ de las ventas.

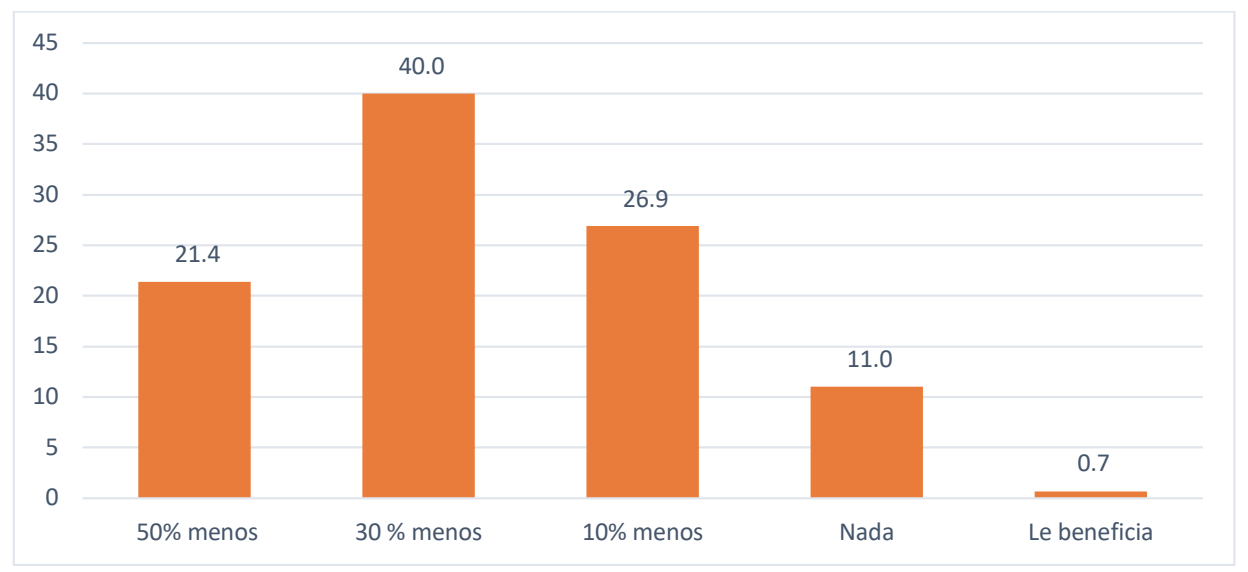

Figura 6. Afectación negativa al comercio en días de lluvias medias en las ciudades estudiadas, en \% Fuente: Autores, 2019. 
La facturación promedio mensual de los comercios es de más de 5 millones de guaraníes en el $59,1 \%$ de los casos, seguido por el grupo de entre 2 y 4 millones de guaraníes mensuales en el $22,6 \%$ de los entrevistados (Figura 7).

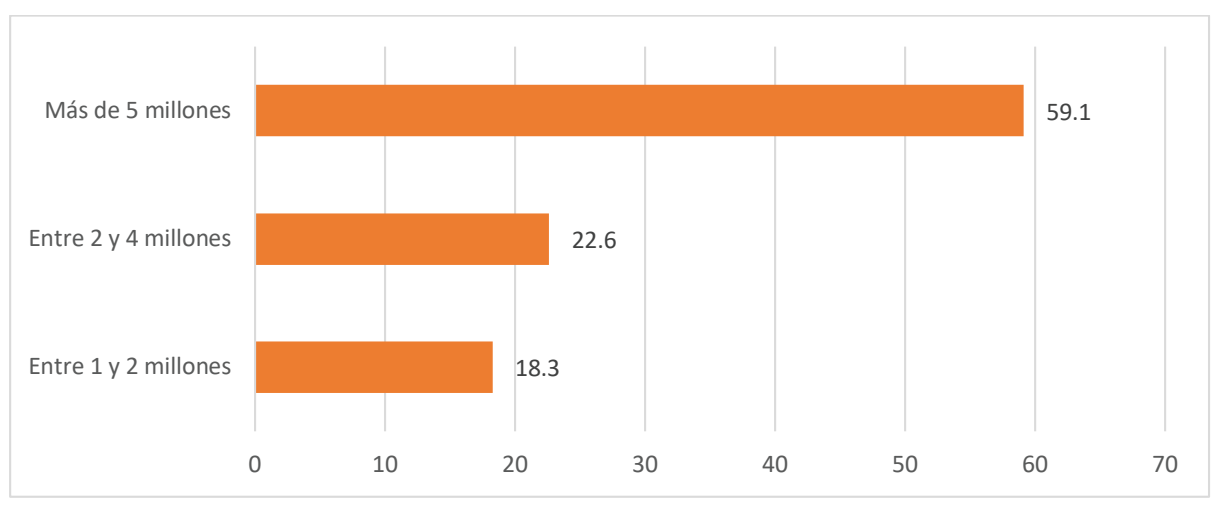

Figura 7. Facturación mensual de los comercios, en guaraníes Fuente: Autores, 2019

Por lo general, el mayor impacto de las lluvias grandes (Figura 8) ocurre en horas de la mañana, impactando un $67,8 \%$ en las ventas de dicha jornada, para luego reducirse considerablemente, llegando a afectar un $28,8 \%$ de las ventas de la tarde.

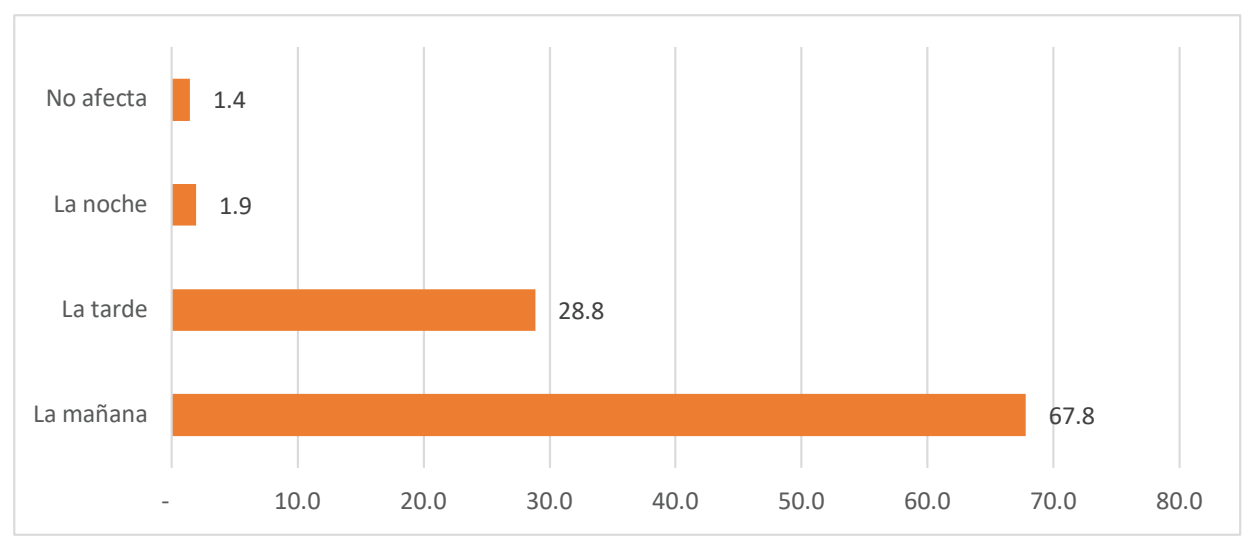

Figura 8. Nivel de afectación de las lluvias grandes que se producen en horas de la mañana, en \% Fuente: Autores, 2019

\section{Principales resultados por ejes comerciales de las ciudades}

Cada eje comercial de las distintas ciudades muestra diferencias a veces significativas que se relacionan con la topografía del lugar, casi siempre zonas bajas, donde las lluvias generan inundaciones con mayor frecuencia y facilidad. Los factores determinantes del grado de afectacion de los ejes comerciales son la topografía de las avenidas y la existencia o no de arroyos en la zona. Estos dos factores combinados pueden afectar de forma significativa la actividad comercial en días de lluvia y, no debe olvidarse, en algunos tramos de los ejes, generalmente los situados en la parte más baja y allí donde el eje o avenida se intersecta con un arroyo.

La altura promedio de las ciudades, no de los centros comerciales, se aprecia en la Tabla 3. Llama la atención la mayor altura sobre el nivel del mar de Lambaré, Fernando de la Mora y Luque, todas estas con más de 120 metros sobre el nivel del mar ya que, como se verá posteriormente, estas ciudades se ven más afectadas en el comercio por las lluvias grandes.

\begin{tabular}{ll} 
Altura promedio de las ciudades & Metros sobre el nivel del mar \\
\hline Lambaré & 156 \\
\hline Fernando de la Mora & 143 \\
\hline Luque & 120 \\
\hline San Lorenzo & 119 \\
\hline
\end{tabular}

(Continúa en la siguiente página) 
(Continuación)

\begin{tabular}{ll} 
Altura promedio de las ciudades & Metros sobre el nivel del mar \\
\hline Villa Elisa & 116 \\
\hline Limpio & 80 \\
\hline Mariano Roque Alonso & 64 \\
\hline Nemby & 64 \\
\hline
\end{tabular}

Tabla 3. Altura promedio de ciudades

Fuente: Autores, 2019, a partir de fuentes diversas.

Lambaré y Fernando de la Mora aparecen como las ciudades con mayor impacto en los días de lluvias grandes, con porcentajes de afectación a ventas superiores al $60 \%$.

Se puede apreciar en la Tabla 4, que las zonas más afectadas por los días de lluvias grandes son Lambaré, Fernando de la Mora, en sus dos ejes, y Limpio, con más del $50 \%$ de entrevistados que indican que sus ventas se reducen de entre el 70 y el $100 \%$.

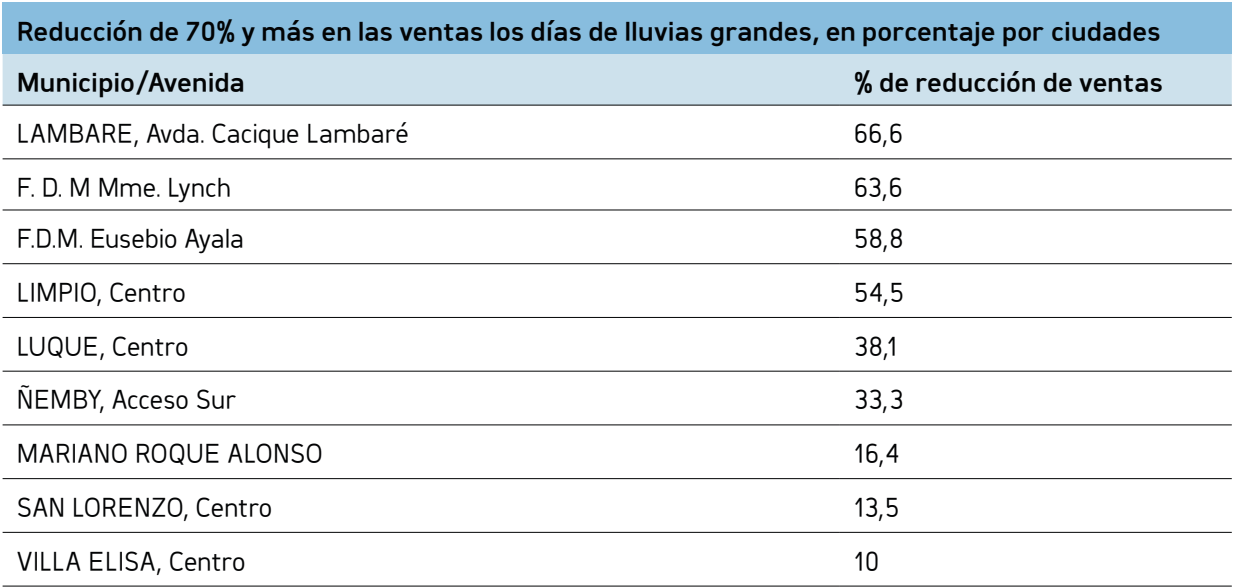

Tabla 4. Zonas más afectadas por municipio

Fuente: Autores, 2019.

En caso de las lluvias medias, otra vez Lambaré y Fernando de la Mora, esta vez en su eje de Eusebio Ayala, y Limpio muestran una disminución de entre 30 y 50\% de sus ventas en los días de Iluvia como se refleja en la Tabla 5.

\begin{tabular}{ll} 
Reducción entre 30 y $\mathbf{5 0 \%}$ en las ventas los días de lluvias medias, en porcentaje por ciudades \\
Municipio/Avenida & $\%$ de reducción de ventas \\
\hline LAMBARE, Avda. Cacique Lambaré & 100 \\
\hline F.D.M. Eusebio Ayala & 76,5 \\
\hline LIMPIO, Centro & 76,5 \\
\hline F. D. M Mme. Lynch & 68,2 \\
\hline SAN LORENZO, Centro & 68,2 \\
\hline NEEMBY, Acceso Sur & 61,9 \\
\hline LUQUE, Centro & 55 \\
\hline VILLA ELISA, Centro & 45 \\
\hline MARIANO ROQUE ALONSO & 39,1 \\
\hline
\end{tabular}

Tabla 5. Afectación en días de lluvias medias Fuente: Autores, 2019

\section{Principales resultados por ciudades}

Se aprecia una variabilidad relativamente alta entre las ciudades estudiadas. Mientras que las lluvias grandes afectan con mayor intensidad a algunas, en otras ciudades los efectos son significativamente menores, esto puede deberse al trazado de las avenidas o ejes comerciales que pueden situarse en zonas de menor impacto por inundaciones, específicamente por situarse en zonas altas y lejos de arroyos.

Por lo general, el factor que determina las inundaciones urbanas y específicamente en los corredores comerciales estudiados es la ubicación geográfica relativa, es decir la posición de los ejes 
de actividad económica en zonas bajas que, en días y periodos de lluvia grande y media, terminan recibiendo grandes cantidades de agua proveniente de las zonas más altas. Un factor que agrava esta situación es la inexistencia de infraestructura pluvial acorde a las actividades, tamaño de la población y las viviendas. No existen en forma suficientes desagües pluviales ni otras medidas que al menos logren mitigar los efectos de las inundaciones.

El caso de la Avenida Cacique Lambaré en el distrito de Lambaré es el que muestra los mayores niveles de afectación al comercio, donde más del $60 \%$ de los comercios ven sus ventas disminuidas en los días de grandes lluvias (Figura 9).

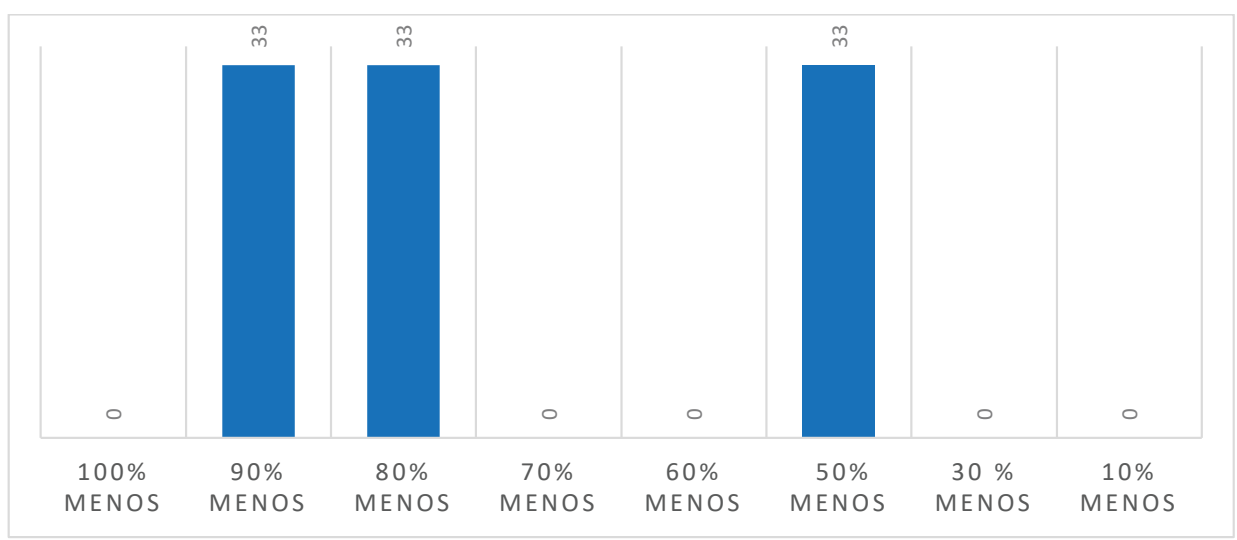

Figura 9. Disminución de ventas en días de lluvias grandes en Lambaré, en \% Fuente: Autores, 2019.

La ciudad de Fernando de la Mora (Figura 10) muestra una distribución relativamente equilibrada en cuanto a la afectación al sector comercial y de servicios en los días de lluvias grandes.

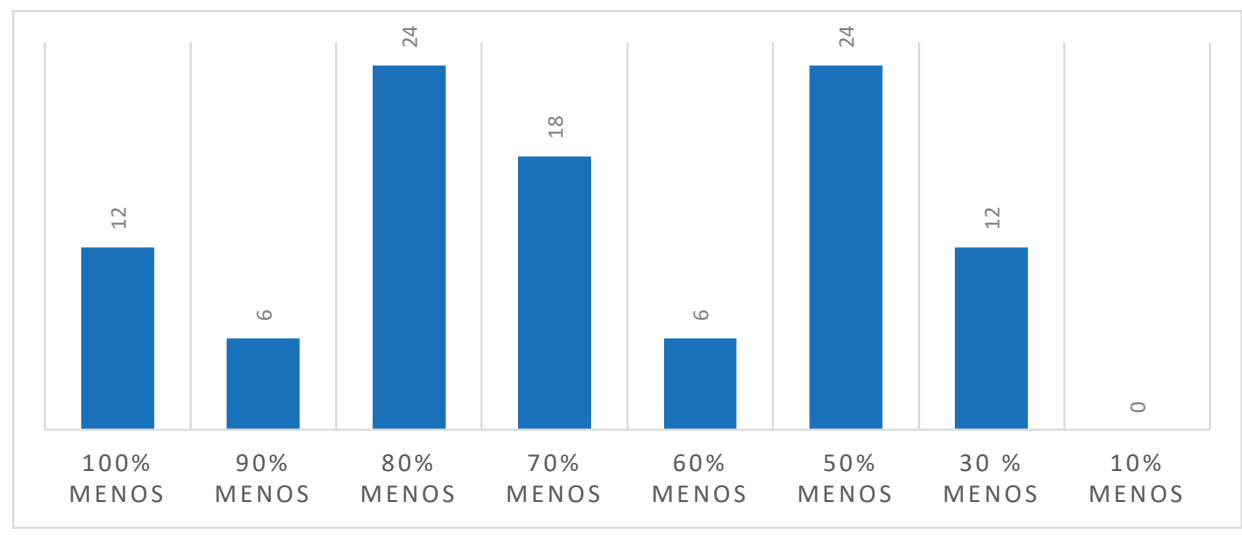

Figura 10. Disminución de ventas en días de lluvias grandes en Fernando de la Mora, en \% Fuente: Autores, 2019.

En el caso de la ciudad de Luque (Figura 11), se observa que la mayoría de los comercios tienen una afectación negativa en niveles superiores al 50\% en el descenso de ventas en días de lluvias grandes.

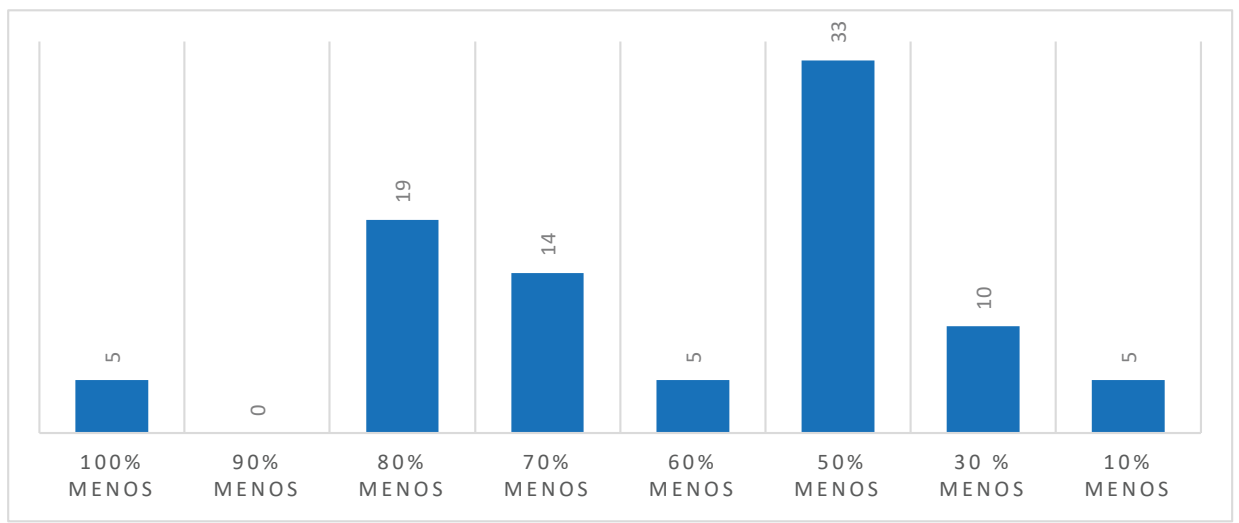

Figura 1l. Disminución de ventas en días de lluvias grandes en Luque, en \%

Fuente: Autores, 2019. 
La ciudad de Limpio (Figura 12), situada al norte de Asunción y a orillas del rio Paraguay, presenta también altos niveles de incidencia negativa en las ventas. La ubicación de la ciudad en una zona relativamente baja podría explicar en parte esta situación.

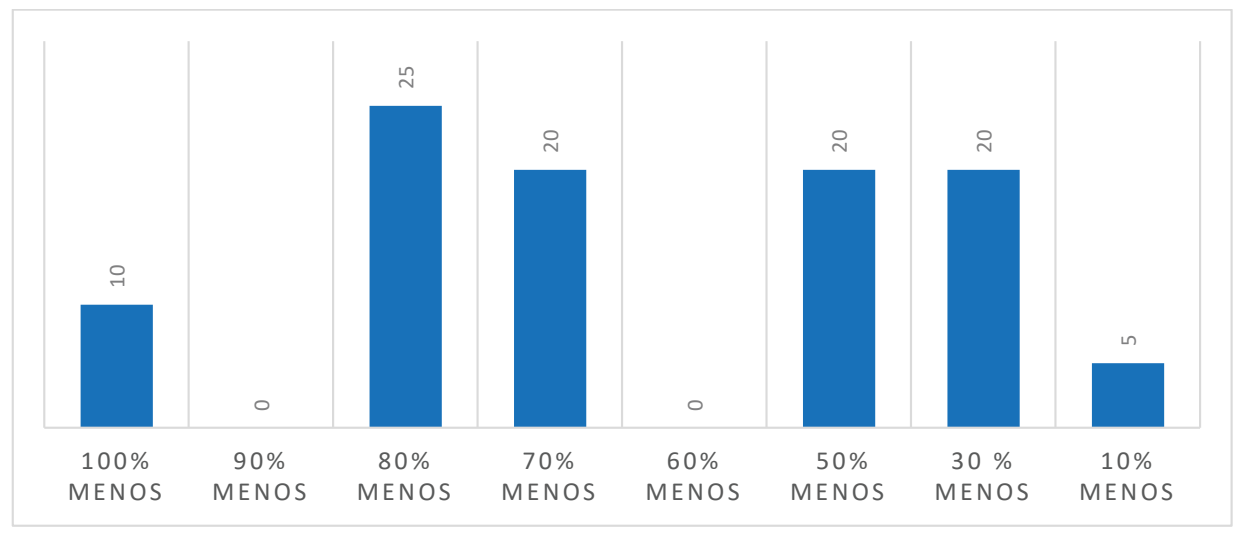

Figura 12. Disminución de ventas en días de lluvias grandes en Limpio, en \% Fuente: Autores, 2019

La ciudad de Villa Elisa (Figura 13) muestra un mejor desempeño que el resto de las ciudades, aunque los propietarios manifiestan altos porcentajes de disminución de ventas en los días de lluvias grandes.

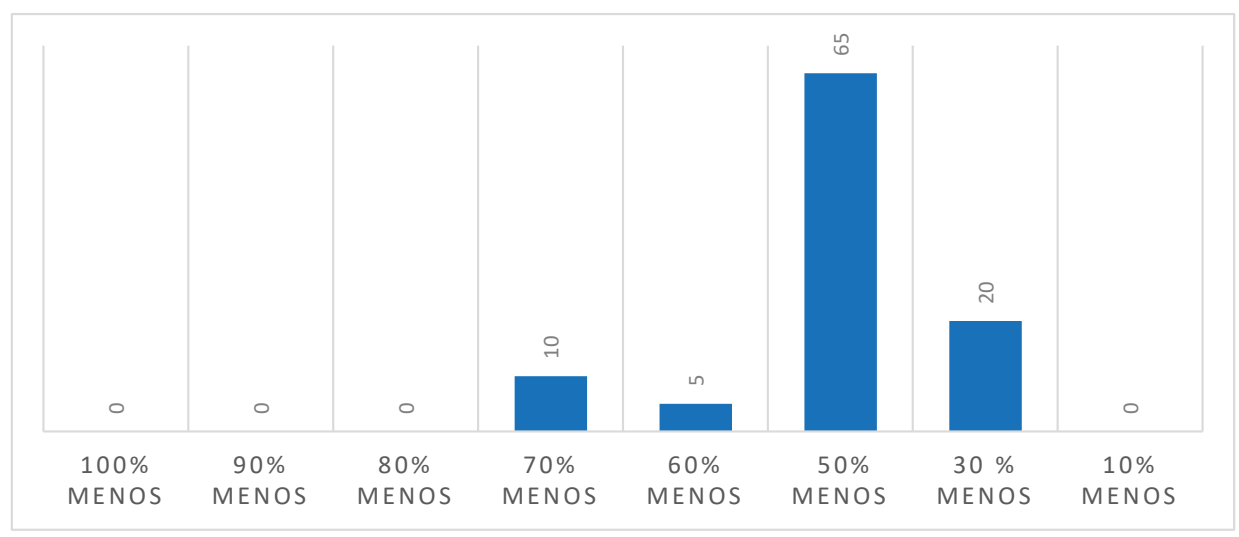

Figura 13. Disminución de ventas en días de lluvias grandes en Villa Elisa, en \% Fuente: Autores, 2019

En la ciudad de Nemby (Figura 14) y en Calle Ultima (Figura 15) se aprecia un nivel de afectación bastante más elevado que otras ciudades, en el caso de las lluvias grandes, donde existen una alta cantidad de comercios que indican que sus ventas se reducen más del $50 \%$.

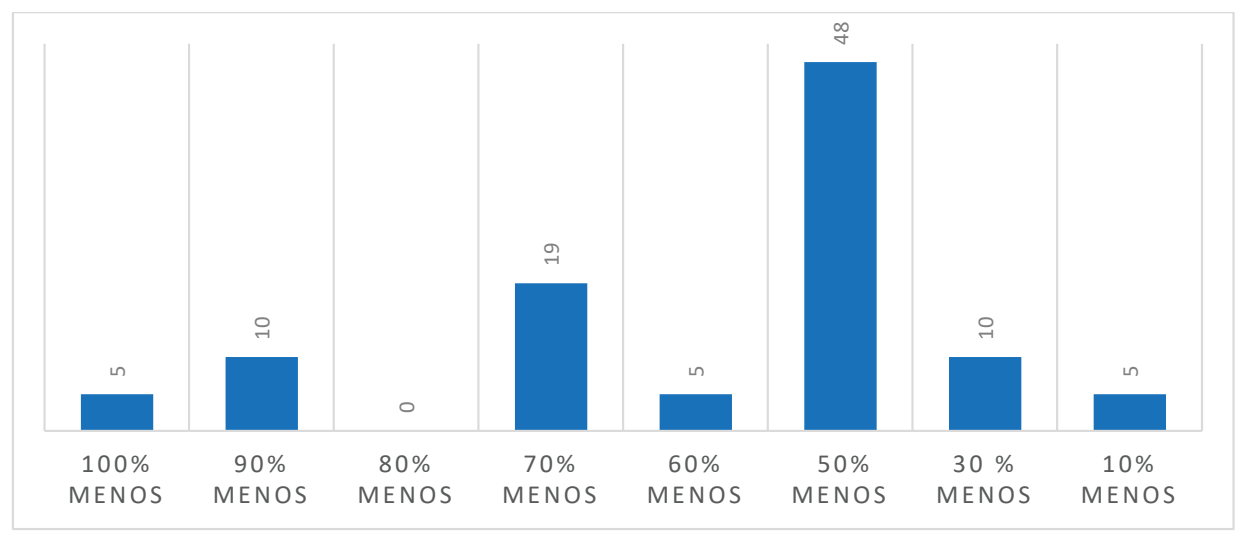

Figura 14. Disminución de ventas en días de lluvias grandes en Ñemby, en \% Fuente: Autores, 2019. 


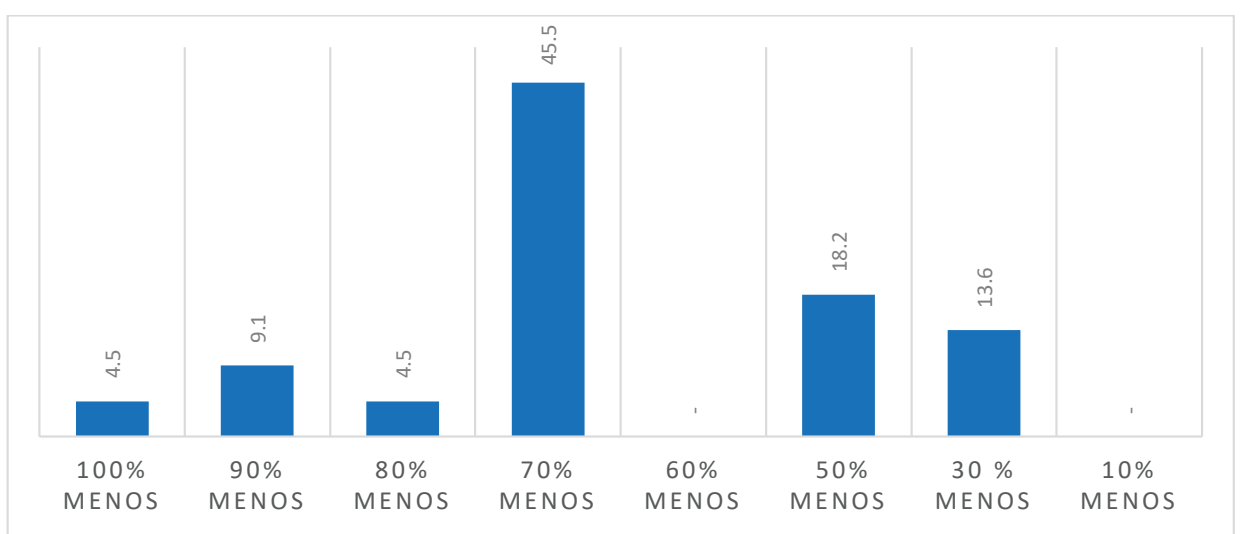

Figura 15. Disminución de ventas en días de lluvias grandes en Calle Ultima, en \% Fuente: Autores, 2019.

La ciudad de San Lorenzo (Figura 16) es la ciudad que menos efecto negativo recibe en los días de lluvia, quizás por la relevancia y envergadura del comercio en esta ciudad.

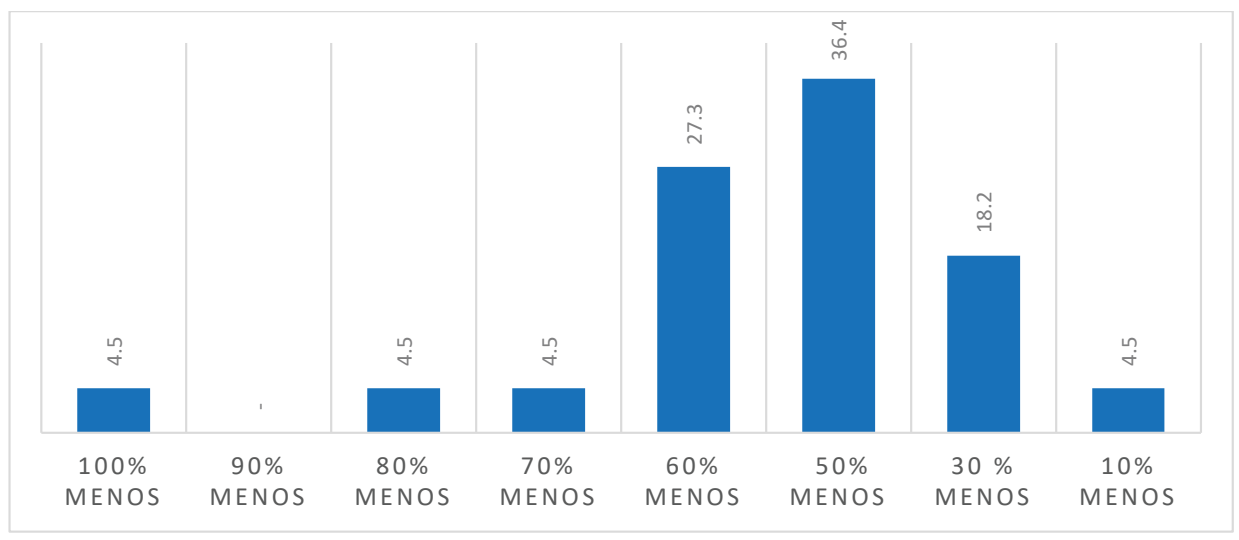

Figura 16. Disminución de ventas en días de lluvias grandes en San Lorenzo, en \% Fuente: Autores, 2019.

La ciudad de Mariano Roque Alonso (Figura 17) muestra un nivel elevado de impacto negativo en cuanto a la reducción de ventas en días de lluvias grandes.

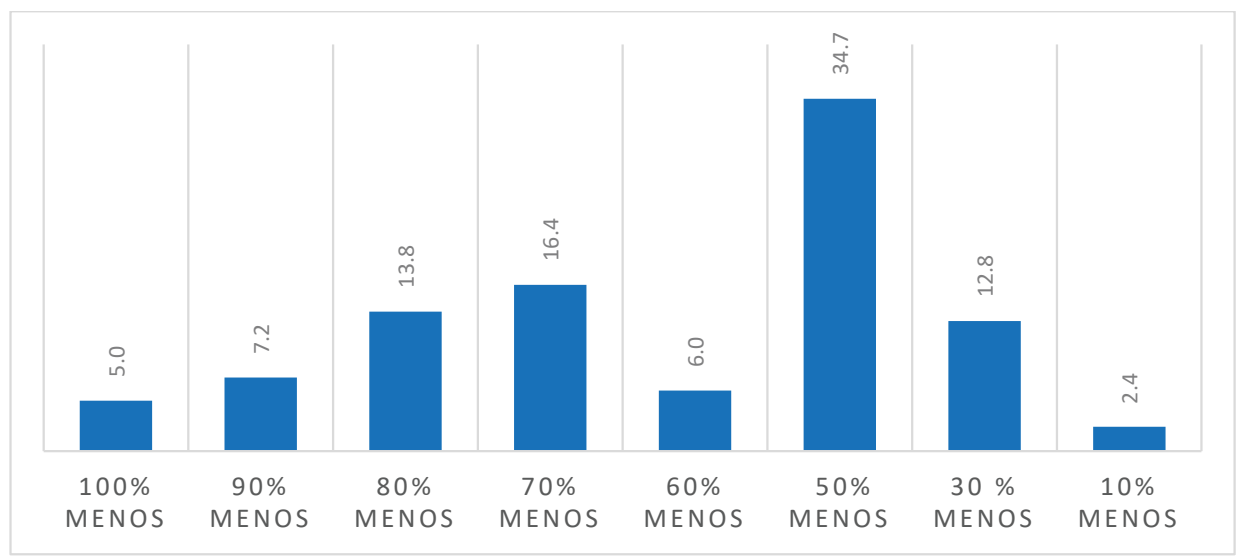

Figura 17. Disminución de ventas en días de lluvias grandes en Mariano Roque Alonso, en \% Fuente: Autores, 2019.

\section{Facturación de los comercios}

Un aspecto fundamental para calcular estimativamente el efecto de las precipitaciones en la dinámica comercial y de servicios es conocer la facturación mensual de los mismos (ver Figura 18 y 19). Casi el $60 \%$ de los comercios encuestados refirió ingresos mensuales superiores a $\$ 5$ millones de guaraníes (US\$900), seguido por el $22,6 \%$ que indicó que la facturación mensual era de entre $\$ 2$ y $\$ 5$ millones de guaraníes (US\$365-900) y un 18,3\% con facturación mensual entre $\$ 1$ y $\$ 2$ millones de guaraníes (US\$185-365). 


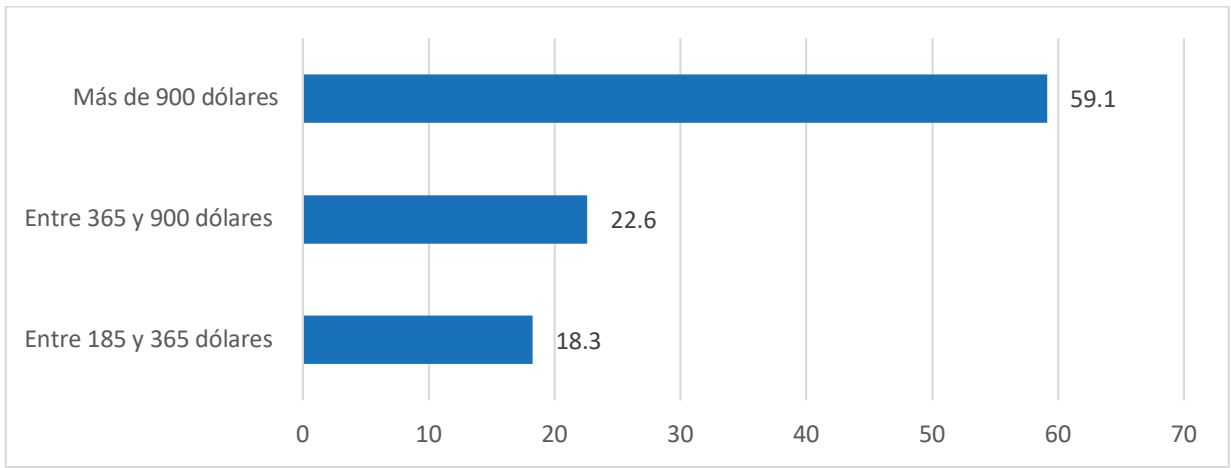

Figura 18. Facturación mensual de los comercios, en \% Fuente: Autores, 2019

Al observar los promedios de ingresos por ciudades se aprecia que todas las ciudades, con excepción de Lambaré presentan muy altos porcentajes de comercios con ingresos mensuales por encima de cinco millones de guaraníes.

Aunque el cuestionario no relevó información referente al tamaño del comercio, se conoce que la gran mayoría de los mismos son considerados pequeñas y medianas empresas, casi siempre conformada por miembros de una familia.

Estimando una rentabilidad de al menos el 30\%, entendida como el resultado de restar los ingresos de los costos, se concluye que los comercios y servicios tienen un desempeño económico aceptable a positivo, con variaciones sustantivas según los diferentes rubros.

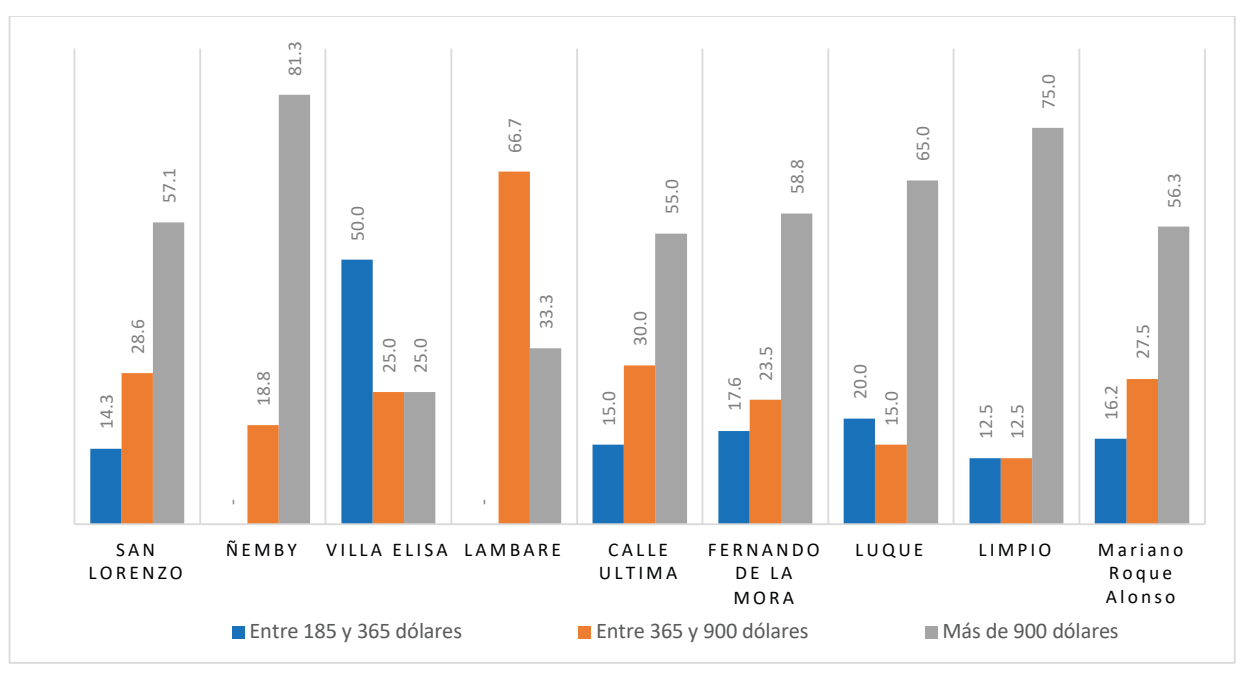

Figura 19. Facturación promedio mensual de los comercios y servicios, en $\%$

Fuente: Autores, 2019

Los periodos de más lluvia en AMA, donde se localizan las ciudades estudiadas, son los meses de verano, desde noviembre a enero, con un pico en abril, para luego disminuir ostensiblemente en el otoño e invierno. Las lluvias en el periodo de mayor cantidad pueden llegar a los 150 milímetros por mes, pero con una distribución muy irregular, es decir que, en un solo día, y en algunas pocas horas pueden caer más de 100 milímetros (ver Figura 20).

La ocurrencia del fenómeno de El Niño ha incrementado los valores pluviométricos, con lo cual el efecto sobre las lluvias sobre la economía ha sido aún más significativo. En las zonas urbanas estudiadas el impacto mayor son las inundaciones pluviales, no solo por la cantidad de lluvia caída, sino sobre todo por la deficiencia y muchos casos inexistencia de infraestructura que permita el desagote rápido y efectivo de la lluvia.

En este punto, la ubicación geográfica y topográfica del eje comercial resulta clave para comprender su nivel de riesgo climático, es decir su capacidad por verse afectado por una inundación pluvial. 


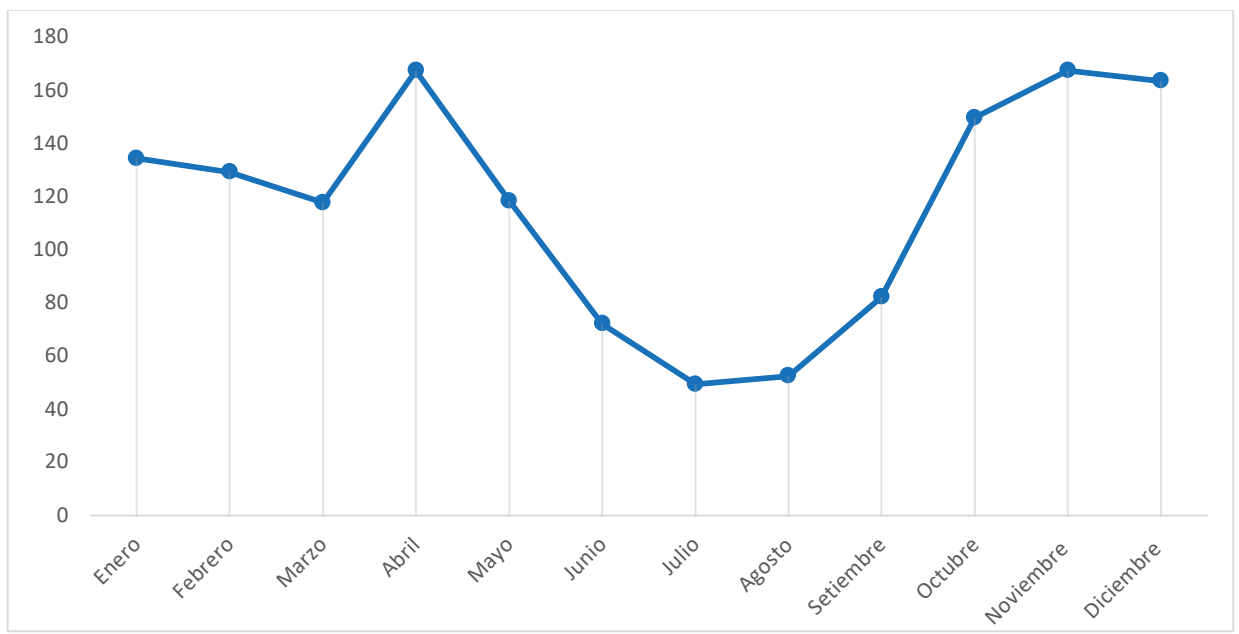

Figura 20. Promedio mensual de precipitaciones en Asunción, en milímetros ( $\mathrm{mm}$ ) Fuente: DINAC, promedio últimos 30 años.

\section{Impactos de las lluvias en la gestión de las Municipalidades}

Las lluvias terminan generando efectos negativos en las infraestructuras viales y sociales de la ciudad, generando costos de reposición de dichas infraestructuras, así como también las tareas de limpieza. Por lo general, y debido a la inexistencia de un sistema de disposición segura de residuos domiciliarios, las familias dejan bolsas de basura en la vereda o en la calle a la espera de la recolección, que se produce solo tres veces por semana. Si ocurre una lluvia, casi siempre existe basura en la vereda que es arrastrada y depositada en las zonas más bajas.

A continuación, en la Tabla 6, se listan las tareas que realizan los municipios luego de acontecido una lluvia.

\begin{tabular}{lll} 
Municipio & Actividad después de un evento de lluvia \\
\hline Luque & - & Recoge la arena que se junta en la calle. \\
& Envía maquinarias para la recolección de basura acumulada en los sumideros \\
& de tormentas \\
\hline M. R. Alonso & - & Limpia la basura del raudal \\
& - & Limpia las ramas caídas \\
& - & Recoge la arena que se junta en la calle \\
& & Asistencia a los afectados, si las tormentas son fuertes. -Asistencia a \\
& damnificados por inundación en conjuntamente con la Secretaria de \\
\hline Nemby & Emergencia Nacional. \\
\hline Lambaré & Limpia la basura del raudal \\
& - & Limpia las ramas caídas \\
& Recoge la arena que se junta en la calle \\
\hline Limpio & Limpia la basura del raudal \\
& - & Limpia las ramas caídas \\
& - & Recoge la arena que se junta en la calle \\
\hline & Limpia la basura del raudal \\
\hline
\end{tabular}

Tabla 6. Tareas realizadas por los municipios luego de lluvias severas Fuente: Autores, 2019 .

El ejercicio a profundidad de valoración de los costos municipales para contrarrestar los efectos negativos de las lluvias no se pudo realizar, pero podría estimarse valorizando la utilización de camiones, tractores, materiales y mano de obra destinados a las reparaciones y recuperación de la infraestructura pública. Las municipalidades arrastran una serie de debilidades institucionales que les impide romper el círculo vicioso de lluvias grandes, daños al patrimonio, gasto en reconstrucción y, otra vez, lluvias grandes. Las municipalidades disponen desde hace cinco años de recursos suplementarios provenientes de royalties por la venta de electricidad de la 
hidroeléctrica de Itaipú, sin embargo, la escasa calidad de la gestión y la casi nula planificación de las municipalidades, difícilmente destinan parte de estos recursos en las infraestructuras para mitigar, controlar y reducir los efectos negativos de las lluvias grandes.

Finalmente, el cálculo del impacto directo de las lluvias en los comercios y servicios es de alrededor de G. 1.560 .000 al año por cada uno de los comercios, calculados a partir de un promedio de ingresos de G. 5.000.000 al mes y una ocurrencia de al menos 15 eventos de lluvias e inundaciones pluviales por año, con una reducción de ventas de al menos el $50 \%$.

Al multiplicar el monto que cada comercio y servicio deja de percibir por ventas (facturación) por la cantidad de los mismos en las ciudades analizadas, se llega a la cifra de US\$10,7 millones de dólares anuales, como se puede apreciar en la Tabla 7.

\begin{tabular}{llll} 
Municipio & $\begin{array}{l}\text { Disminución de facturación } \\
\text { en Comercio, en US } \$\end{array}$ & $\begin{array}{l}\text { Disminución de facturación } \\
\text { en Servicios, en US } \$\end{array}$ & $\begin{array}{l}\text { Total, disminución de la } \\
\text { facturación, en US } \$\end{array}$ \\
\hline San Lorenzo & 1.791 .537 & 1.098 .021 & 2.889 .558 \\
\hline Luque & 1.298 .905 & 833.368 & 2.132 .274 \\
\hline Fernando de la Mora & 844.042 & 762.211 & 1.606 .253 \\
\hline Lambaré & 680.105 & 578.295 & 1.258 .400 \\
\hline Limpio & 528.484 & 251.242 & 779.726 \\
\hline Nemby & 467.179 & 312.821 & 780.000 \\
\hline Mariano Roque Alonso & 433.516 & 306.526 & 740.042 \\
\hline Villa Elisa & 327.874 & 234.000 & 561.874 \\
\hline Total & $\mathbf{6 . 3 7 1 . 6 4 2}$ & $\mathbf{4 . 3 7 6 . 4 8 4}$ & 10.748 .126 \\
\hline
\end{tabular}

Tabla 7. Disminución de facturación anual por efecto de lluvias Fuente: Autores, 2019.

\section{CONCLUSIÓN}

Las lluvias, con sus diferentes intensidades, generan impactos significativos en las actividades económicas urbanas, al limitar, reducir y a veces impedir el desarrollo de las actividades comerciales de las ciudades. En este estudio se apreció una reducción muy significativa y por lo tanto negativa de las actividades comerciales en los ejes comerciales de las ciudades estudiadas.

Las lluvias grandes, medias y ligeras tienen un impacto negativo que está directamente relacionado al volumen de agua caída. Las lluvias grandes afectan bastante el desempeño comercial, reduciendo en todas las ciudades más del 50\% de las ventas del día. La ubicación y la topografía de los ejes comerciales de las distintas ciudades determinan el nivel de afectación de los mismos en los días y periodos de lluvia.

Si el sector de comercios y servicios genera un dinamismo creciente en la economía paraguaya y especialmente en las nuevas economías urbanas, porque atiende a una demanda cada vez más numerosa, al mismo tiempo de crear empleo, cualquier factor, en este caso las precipitaciones y las inundaciones pluviales, tiene un impacto sensible en los márgenes de los comercios y los servicios. La cifra calculada de afectación a los comercios y servicios de las ciudades estudiadas es de US\$10,7 millones de dólares anuales, es decir una cifra más que considerable para las economías urbanas. En promedio, cada comercio deja de vender 1,5 millones de guaraníes por evento (alrededor de 300 dólares), con un supuesto de ocurrencia de fenómenos climáticos de 15 eventos, y con un nivel de afectación promedio de solo el $50 \%$.

En algunos ejes comerciales, especialmente aquellos desfavorecidos por una ubicación geográfica, es decir aquellos situados en las partes más bajas, el impacto económico es significativamente mayor. Atendiendo que el comercio y los servicios son las fuentes principales de empleo en la zona metropolitana, se concluye que todos los eventos climáticos asociados a las lluvias, en sus diferentes intensidades y frecuencias, tiene un impacto mayor en la capacidad de generar renta, debido a que frena e interfiere en el desarrollo normal de las actividades.

A partir de los datos obtenidos se pueden proponer algunas recomendaciones destinadas a reducir, controlar y administrar los efectos negativos de las inundaciones pluviales. Se asume que 
el margen de maniobra para operaciones de cambios ideales es muy baja y costosa, ya que los ejes comerciales están consolidados, vinculados a la historia de las ciudades y a las prácticas cotidianas de los habitantes.

La primera recomendación es la instalación de sistemas de desagüe pluvial en las zonas urbanas, pues estas permitirán el escurrimiento de las aguas y disminuirán en parte, las inundaciones. Estas obras podrían financiarse tanto por la cooperación internacional como con la utilización de los fondos provenientes de los royalties por venta de electricidad al cual acceden las municipalidades.

La segunda recomendación es la intervención puntual en las zonas más bajas de los ejes más críticos (UCA \& Rivelli, 2014b), consistente en sumideros, canales y señalización (UCA et al., 2018) que mejore la funcionalidad urbana en los periodos de lluvias grandes.

Por último, se precisaría además de una campaña comunicacional que instale estos temas en la agenda ciudadana y política, ya que los fenómenos climáticos como las lluvias suelen ser percibidos como eventos 'divinos' o 'naturales' que no pueden ser gestionados ni administrados.

\section{REFERENCIAS}

Ferreira, M. \& Vázquez, F. (2015). Agricultura y Desarrollo. Asunción: UGP.

Dirección General de Estadística, Encuestas y Censos DGEEC. (2011). Censo Económico Nacional. Asunción: DGEEC.

Dirección General de Estadística, Encuestas y Censos DGEEC. (2016). Proyección de población. Asunción: DGEEC.

Universidad Católica Nuestra Señora de la Asunción UCA, Kumar, D. \& Báez, A. (2018). Señalización de puntos críticos y propuesta de desvíos alternativos como medida de mitigación sostenible a impactos por eventos hidrometeorológicos severos. Asunción: UCA.

Universidad Católica Nuestra Señora de la Asunción UCA, Báez, J. \& Monte Domecq, R. (2017). Estudio de riesgos sobre los distintos niveles de crecidas del río Paraguay en los Municipios de Limpio, Mariano Roque Alonso, Lambaré y Villa Elisa. Asunción: UCA.

Universidad Católica Nuestra Señora de la Asunción UCA \& García, R. E. (2017a). Proyecto INV-440 Gestión de Riesgo de Inundaciones en Municipios del Departamento Central - Protocolo de Alerta Temprana SEN-DMH. Asunción: UCA.

Universidad Católica Nuestra Señora de la Asunción UCA \& García, R. E. (2017b). Proyecto INV-440 Gestión de Riesgo de Inundaciones en Municipios del Departamento Central - Planes de Contingencia para eventos hidrometeorológicos para municipios ocho municipios del departamento Central. Asunción: UCA.

Universidad Católica Nuestra Señora de la Asunción UCA, Báez, J. \& Monte Domecq, R. (2014). Un acercamiento a las inundaciones en el Paraguay. Asunción: UCA.

Universidad Católica Nuestra Señora de la Asunción UCA \& Rivelli, L. (2014a). Diseño de un sistema de alerta temprana de inundaciones urbanas, por medio de la determinación del ciclo diario de la precipitación intensa en el Ârea Metropolitana de la Gran Asunción, utilizando técnicas de radar y satélites meteorológicos. Asunción: UCA.

Universidad Católica Nuestra Señora de la Asunción UCA \& Rivelli, L. (2014b). Identificación de puntos críticos y mitigación de las inundaciones urbanas de Asunción. Asunción: UCA. 